\title{
ANALISIS KEMAMPUAN PEMECAHAN MASALAH MATEMATIS SISWA MENGGUNAKAN MODEL PEMBELAJARAN TEAM GAMES TOURNAMENT SMA MUHAMMADIYAH 1 PURWOKERTO
}

\author{
Desy Puspitasari ${ }^{1}$, Sari Muliawanti ${ }^{2}$, Gunawan $^{3}, \operatorname{Sairan}^{4}$ \\ ${ }^{1,2,3}$ Universitas Muhammadiyah Purwokerto \\ ${ }^{4}$ SMP Negeri 1 Gumelar \\ E-mail : desypuspita989@gmail.com ${ }^{1)}$ \\ sarimuliawanti2@gmail.com ${ }^{2}$ \\ gun.oge@gmail.com ${ }^{3)}$ \\ sairan.uny@gmail.com ${ }^{4)}$
}

Received 12 December 2018; Received in revised form 24 March 2019; Accepted 8 May 2019

\begin{abstract}
The purpose of this study is describing the mathematical problem solving ability using the TGT (Teams Games Tournament) learning model for the students of SMA Muhammadiyah 1 Purwokerto. This study uses qualitative research methods using the Miles and Huberman model which includes data reduction, data display, and conclusion (verification/conclusion drawing). The subjects of this study are students of X IPA 1 SMA Muhammadiyah 1 Purwokerto. By using purposive sampling technique, the students of $X$ IPA 1 were in three groups: the group of low achieving students, the group of medium achieving students, and the group of high achieving students. In each group, three students were selected to become respondents and then analyzed. Data collection methods in this study use questionnaire, tests, interviews, and documentation. From the results of this study, obtained: 1) the students with low achievement have a poor problem-solving ability, 2) the students with medium achievement have a good problem-solving ability, 3) the students with high achievement have great problem-solving skills.
\end{abstract}

Keywords: Ability in Mathematics Problem-solving; TGT.

PENDAHULUAN

Matematika merupakan salah satu bidang ilmu yang aplikatif dalam kehidupan sehari- hari. Permasalahan yang muncul sebagian dapat diselesaikan menggunakan konsep matematika. Salah satu contohnya, pada masalah ekonomi. Bagaimana cara seseorang dapat membuat perabotan rumah dengan pengeluaran bahan yang relatif sedikit tetapi menghasilkan keuntungan yang maksimal. Hal tersebut dapat diselesaikan menggunakan konsep matematika program linear. Sehingga, ilmu matematika tidak dapat lepas dari kehidupan sehari- hari salah satunya dalam memecahkan suatu masalah.
Pemecahan

masalah merupakan salah satu kemampuan dasar yang harus dikuasai oleh siswa. Di dalam pemecahan masalah, siswa tidak hanya dapat untuk memecahkan masalah tetapi juga dapat mengembangkan kemampuan berpikirnya. Pentingnya memiliki kemampuan pemecahan masalah oleh siswa dalam matematika juga dikemukakan oleh (Ismawati, 2014), kemampuan pemecahan masalah amatlah penting bukan saja bagi mereka yang kemudian hari akan mendalami matematika, melainkan juga bagi mereka yang akan menerapkannya dalam bidang studi lain maupun kehidupan sehari-hari. Siswa di SMA Muhammadiyah khususnya kelas X IPA 1 mengalami kesulitan dalam 
menyelesaikan soal matematika. Hal tersebut dibuktikan dengan tidak dapat menerapkan apa yang diketahui pada soal. Siswa hanya menuliskan yang diketahui dan apa yang ditanyakan saja. Sehingga untuk mengatasi hal tersebut diperlukan suatu model pembelajaran salah satunya model pembelajaran Team Games Tournament (TGT). Hal tersebut sesuai dengan penelitian yang dilakukan oleh (Suji, Nirawati, \& Mariyam, 2017) bahwa TGT dapat meningkatkan kemampuan pemecahan matematis siswa.

\section{Dalam pembelajaran}

matematika, kemampuan pemecahan masalah merupakan hal yang penting. (Warli, 2013) menyatakan bahwa pemecahan masalah dalam ilmu matematika, sains, bisnis, dan kehidupan sehari-hari merupakan tujuan pokok dalam pembelajaran matematika. Menurut (Polya, 1973) menyebutkan ada empat langkah dalam pendekatan pemecahan masalah, yaitu 1) Memahami Masalah, 2) Merencanakan Penyelesaian, 3) Melaksanakan Rencana, dan 4) Memeriksa Kembali. Kemampuan pemecahan masalah matematis setiap siswa berbeda-beda. Perbedaan kemampuan pemecahan siswa dapat disebabkan karena dalam kegiatan belajar setiap siswa memiliki motivasi belajar dengan tingkatan yang berbeda. Menurut (Kim, 2012), kemampuan pemecahan masalah siswa dapat ditingkatkan melalui pembelajaran yang berpusat pada siswa (student centered). Salah satu model pembelajaran tersebut adalah model pembelajaran kooperatif. Hasil penelitian (Winarni, 2014) menyatakan bahwa guru Matematika sebaiknya menggunakan model pembelajaran kooperatif dalam menerapkan pendekatan saintifik. Selain itu. (Isjoni, 2009) menyatakan bahwa pembelajaran kooperatif dapat meningkatkan belajar siswa yang lebih baik dan meningkatkan sikap saling tolong menolong dalam perilaku sosial.

Pembelajaran kooperatif sangat banyak tipenya, salah satunya pembelajaran kooperatif tipe Teams Games Tournaments (TGT). Pembelajaran kooperatif tipe TGT terdapat tahapan-tahapan yang dirasa dapat meningkatkan motivasi siswa dalam mengikuti pembelajaran matematika serta menjadikan siswa untuk memiliki sikap yang baik dan positif terhadap matematika. Adapun tahapan dalam pembelajaran kooperatif tipe TGT sebagaimana disebutkan oleh (E. R. Slavin, 2008) yaitu presentasi kelas, belajar kelompok, game, turnamen, dan penghargaan kelompok. Tahapan-tahapan tersebut sangat penting untuk menunjang dan meningkatkan motivasi siswa dalam belajar matematika. Game dan tournament diharapkan dapat membuat siswa lebih termotivasi untuk belajar matematika, lebih kreatif, menumbuhkan sikap positif pada siswa, menghormati teman, dan tepat dalam menyelesaikan masalah matematika (R. E. Slavin, 2008). Selain itu, hasil penelitian (Tampubolon, 2013) menyatakan bahwa model pembelajaran TGT dapat meningkatkan kemampuan pemecahan dan pemahaman Matematika. Karakteristik utama pada artikel ini adalah analisis TGT terhadap kemampuan pemecahan masalah matematis siswa pada tingkat Sekolah Menengah Atas (SMA) khususnya di SMA Muhammadiyah 1 Purwokerto. Selain itu, TGT sangat baik untuk meningkatkan kemampuan penalaran matematis (Rahmawati, 2017), prestasi belajar dan berpikir kritis (Armita \& Marsigit, 2016), hasil belajar (Rustinah, 2016), prestasi dan motivasi (Trisnawati $\&$ Wutsqa, 2015). Pada penelitian (Suji et al., 2017) dan (Bakoban \& Amry, 
2017) berfokus kemampuan pemecahan masalah pada Sekolah Menengah Pertama (SMP). Hal tersebut menjadi motivasi untuk menganalisa kemampuan pemecahan masalah matematis menggunakan TGT di SMA Muhammadiyah Purwokerto. Adapun tujuan dalam penelitian ini adalah untuk mendeskripsikan kemampuan pemecahan masalah matematis siswa menggunakan model pembelajaran TGT (Team Games Tournament) pada siswa SMA Muhammadiyah 1 Purwokerto. Hasil deskripsi tersebut dapat digunakan sebagai bahan pertimbangan guru dalam melaksanakan kegiatan pembelajaran di kelas dan menentukan strategi pembelajaran yang efektif.

\section{METODE PENELITIAN}

Metode penelitian yang digunakan adalah metode penelitian deskriptif dengan pendekatan kualitatif. Artikel ini akan memberikan gambaran yang lebih mendalam mengenai kemampuan pemecahan masalah matematis siswa kelas X IPA di SMA Muhammadiyah 1 Purwokerto. Prosedur penelitian ini meliputi tiga tahapan utama yaitu: tahap persiapan, pelaksanaan, dan analisis data. Hal-hal yang dilakukan pada saat persiapan diantaranya: menentukan sampel penelitian menggunakan teknik purposive sampling, penyusunan soal dan pedoman wawancara. Dalam hal ini pengambilan sampel berdasarkan hasil UTS siswa. Diambil masing-masing siswa dari setiap kategori, yaitu kategori rendah, sedang dan tinggi. Pada saat pelaksanaan, dilakukan pengambilan data tentang kemampuan pemecahan masalah matematis siswa dengan cara tes dan wawancara. (Sugiyono, 2012) menyebutkan bahwa metode penelitian kualitatif adalah metode penelitian yang digunakan untuk meneliti pada kondisi obyek yang alamiah, dimana peneliti adalah sebagai instrument kunci, teknik pengumpulan data yang dilakukan secara triangulasi (gabungan), analisis data bersifat induktif, dan hasil penelitian kualitatif lebih menekankan makna dari pada generalisasi. Mereduksi berarti merangkum, memilih hal-hal pokok, dan memfokuskan pada masalah yang ingin dianalisis. Dengan reduksi data, maka gambaran kemampuan pemecahan masalah matematis akan semakin jelas. Setelah data direduksi, kemudian data disajikan. Penyajian data dilakukan dalam bentuk uraian singkat, bagan, atau hubungan antar kategori, Dengan penyajian data, maka akan memudahkan memahami apa yang terjadi, dan dapat digunakan untuk merencanakan apa yang akan dilakukan selanjutnya. Langkah selanjutnya adalah penarikan kesimpulan dan triangulasi data. Hasil kesimpulan berupa gambaran tentang kemampuan pemecahan masalah matematis siswa kelas X IPA SMA Muhammadiyah 1 Purwokerto.

\section{HASIL PENELITIAN DAN PEMBAHASAN}

Menurut (Polya, 1973) bahwa terdapat empat langkah dalam pemecahan masalah matematika, yaitu :

1. Memahami masalah.

2. Menyusun rencana penyelesaian.

3. Melaksanakan rancangan pemecahan masalah.

4. Memeriksa kembali hasil yang diperoleh.

Materi yang digunakan untuk soal post test adalah komposisi dan invers fungsi. Terdapat 3 soal post test. Masing- masing soal digunakan untuk mengetahui indikator kemampuan pemecahan masalah matematis siswa. 
Jumlah responden yang dianalisis sebanyak 9 siswa. Masing- masing 3 responden dari tiap kelompok rendah, tinggi, dan sedang. Berikut ini soal post test yang digunakan:

1. Diketahui $f(x)=\frac{x-3}{2 x+5}, x \neq-\frac{5}{2}$.

Tentukan $f^{-1}(x)$.

2. Diketahui fungsi

$f(x)=x^{2}+2 x$ dan $g(x)=x-3$.

Tentukan rumus fungsi komposisi $(f \circ g)(x)$.
3. Diketahui $f(x)=2-3 x$ dan $g(x)=$ $x+1$. Tentukan $(g \circ f)^{-1}(0)$.

Selanjutnya, akan dijelaskan tentang kemampuan pemecahan masalah matematis siswa dari masingmasing responden. Untuk menjelaskan kemampuan pemecahan matematis masing- masing kategori, akan diambil 1 responden dari setiap kategori rendah, sedang, dan tinggi. Pengambilannya berdasarkan nilai tertinggi dari setiap responden masing- masing kategori.

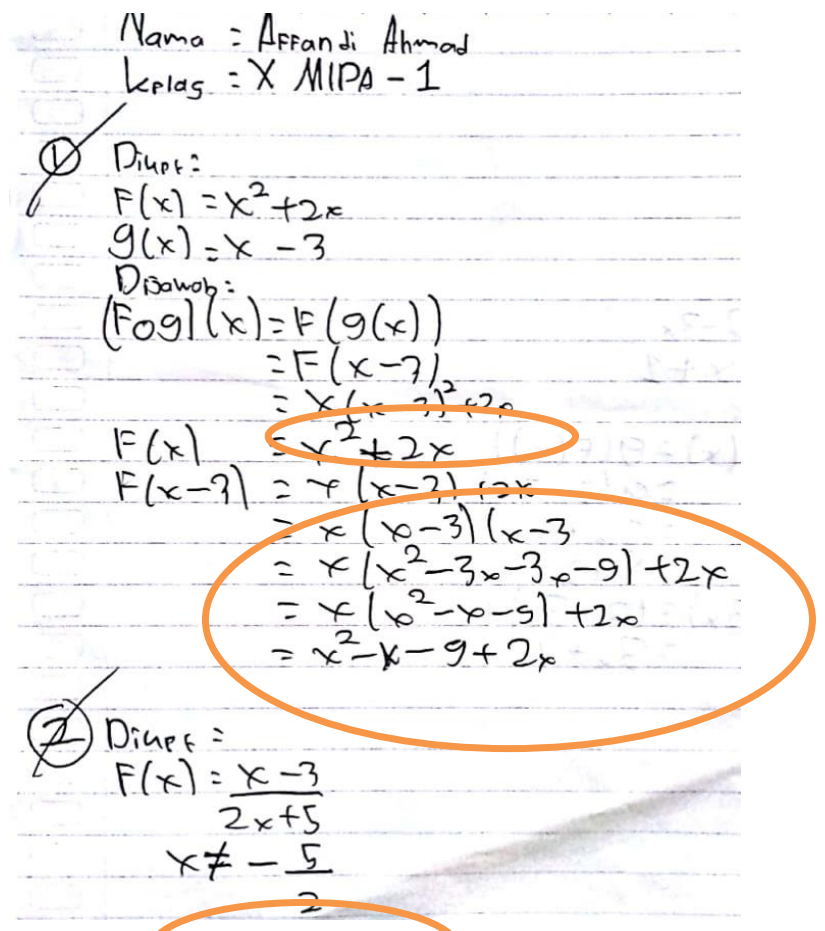

Gambar 1. JawaEan responden 1 whtuk butir soal nomor 1 dan 2

\section{Responden Kategori Rendah}

Berdasarkan Gambar 1 di atas, responden 1 hanya menjawab butir soal 1 dan 2 . Untuk soal butir 1 , responden dapat menjawab soal dengan benar. Responden dapat memahami soal dengan baik dibuktikan dengan menuliskan maksud dari $(f \circ g)(x)=f g(x)$ kemudian mensubstitusikan fungsi $g(x)=x-3$ ke dalam fungsi $f(x)$. Pada proses jawaban, responden tidak mengganti $x$ pada fungsi $f(x)$ dengan $x-3$. Kemudian, responden menuliskan kembali dari awal. Tetapi, terdapat kesalahan pada penulisan fungsi $f(x)$ sehingga berakibat jawaban yang salah. Untuk soal butir 2, responden tidak dapat menjawab soal dengan benar. Artinya, responden tidak dapat memahami soal. Responden hanya menuliskan syarat fungsi $f$ agar terdefinisi. 


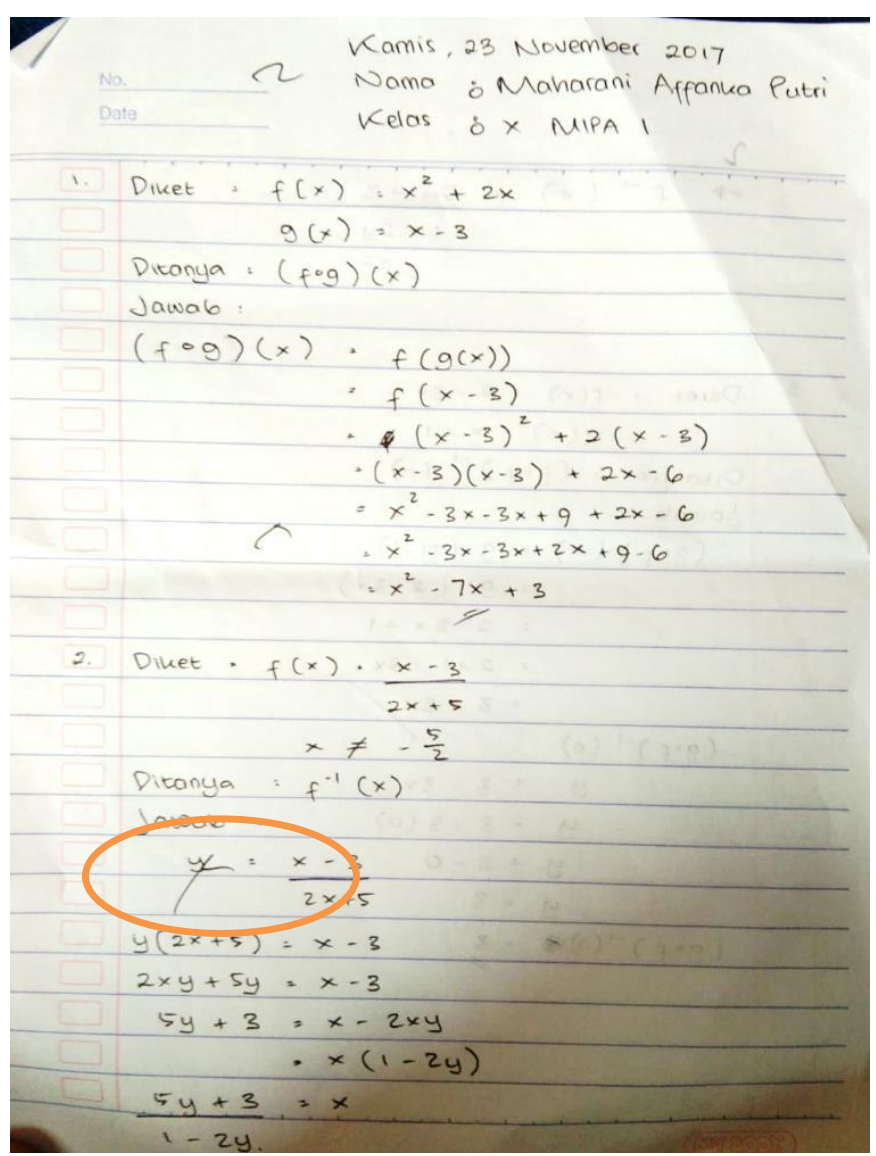

Gambar 2. Jawaban responden 2 untuk butir soal nomor 1 dan 2

\section{Responden kategori sedang}

Berdasarkan jawaban butir soal 1 pada Gambar 2, responden 2 sudah menuliskan jawaban dengan benar dan jelas. Menuliskan terlebih dahulu fungsi $f(x)$ dan $g(x)$ kemudian menuliskan yang ditanyakan yaitu $(f \circ g)(x)$. Dalam menuliskan jawaban, responden mensubstitusikan rumus fungsi $g(x)$. Kemudian dalam menghitung aljabar, jawaban responden sudah benar. Untuk butir soal 2, responden 2 dapat mengerjakan yang ditanyakan. Responden menggunakan perkalian silang untuk memperoleh fungsi $x$ dalam $y$. Sudah dapat menemukan fungsi $x$ dalam $y$. Tetapi, tidak mengganti $x \quad$ dengan $f^{-1}(x)$. Tetapi, responden 2 tidak mengecek kembali jawaban dengan cara :

$x=\frac{5 y-3}{1-2 y} \Rightarrow x=\frac{5 f(x)-3}{1-2 f(x)} \Rightarrow f^{-1}(x)=\frac{5 f^{-1} f(x)-3}{1-2 f^{-1} f(x)}=\frac{5 x-3}{1-2 x}$. 


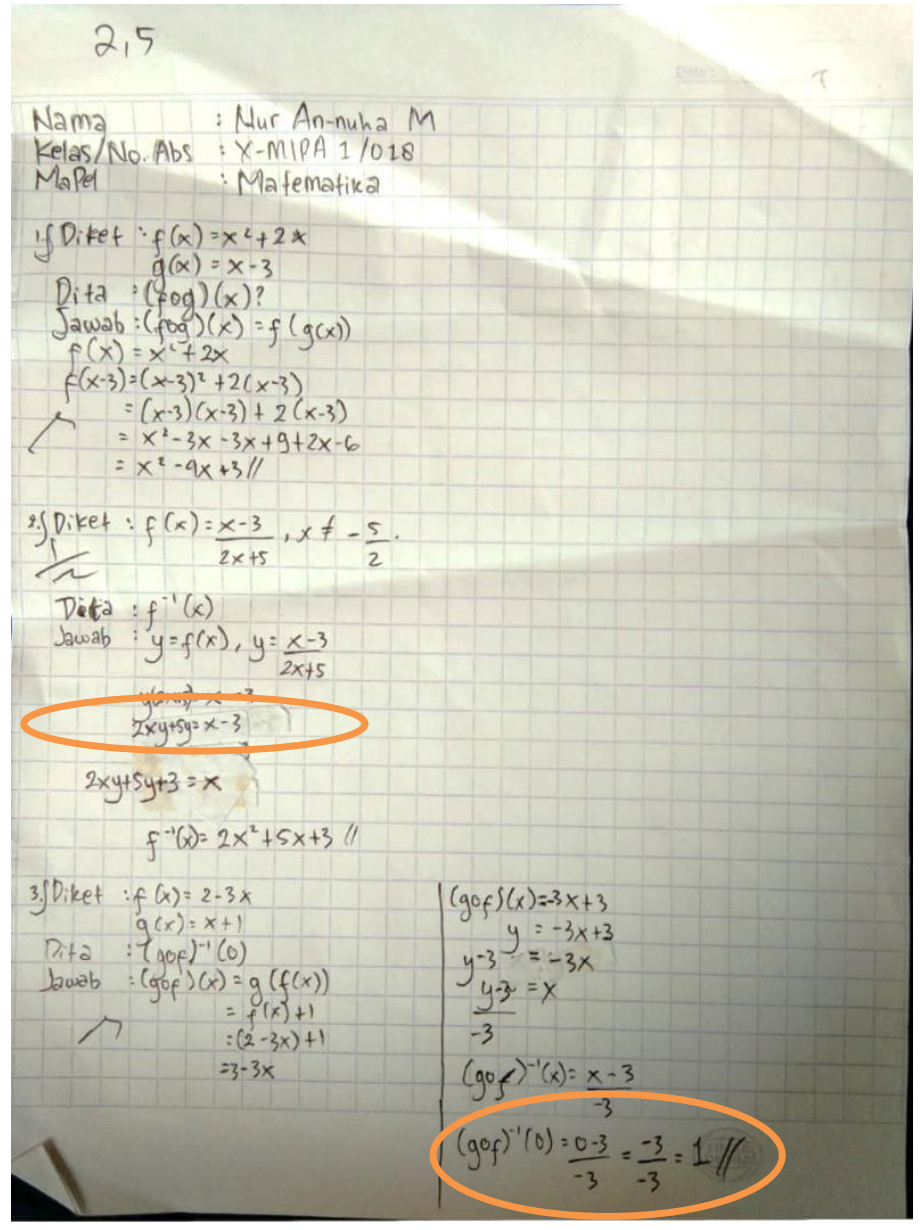

Gambar 3. Jawaban responden 3 untuk butir soal nomor 1, 2, dan 3

3. Responden Kategori Tinggi

Berdasarkan Gambar 3, responden 3 dapat menjawab semua soal. Untuk jawaban soal butir 1, sudah dapat menjawab dengan benar. Responden 3 dapat memahami soal dengan baik dengan mengetahui apa yang ditanyakan. Kemudian, dapat menuliskan apa yang diketahui. Responden juga sudah memahami artinya $(f \circ g)(x)=f g(x)$. Untuk soal butir 2, responden sudah memahami soal dibuktikan dengan menyamadengankan fungsi $f(x)=y$. Kemudian, menggunakan konsep perkalian silang. Pada proses penghitungan aljabar, terdapat kesalahan pada konsep pemfaktoran. Responden tidak memfaktorkan $2 x y+5 y=x-3 \quad$. Seharausnya, difaktorkan ke dalam bentuk $2 x y-x=-5 y-3 \Rightarrow x(2 y-1)=-5 y-3$ Dengan demikian, responden 3 tidak dapat menggunakan konsep pemfaktoran untuk memperoleh fungsi dalam variable $y$. Sehingga, fungsi invers yang dicari tidak dapat ditemukan. Untuk soal butir 3 , responden sudah dapat memahami maksud dari soal. Hal tersebut dibuktikan dengan menentukan terlebih dahulu rumus fungsi $\quad(g \circ f)(x)$ kemudian menentukan rumus fungsi $(g \circ f)^{-1}(x)$ 
dan terakhir menentukan nilai fungsi $(g \circ f)^{-1}(x)$ di $x=0$. Dari ketiga soal di atas, responden 3 tidak memenuhi indikator ke- 4 yaitu tidak memeriksa kembali jawaban yang diperoleh.

Berdasarkan uraian di atas, model pembelajaran TGT menjadi penting untuk meningkatkan kemampuan pemecahan matematis siswa. Siswa cenderung merasa bosan dalam mengerjakan soal matematika apalagi jika siswa belum menguasai materi. Untuk menumbuhkan motivasi siswa diperlukan suatu model pembelajaran yang menyenangkan dan menikmati sehingga siswa dapat lebih mudah menyelesaikan masalah matematika. Hal ini sejalan dengan penelitian (Suji et al., 2017) bahwa model pembelajaran TGT dapat meningkatkan kemampuan pemecahan masalah matematis siswa. Dengan tulisan ini, guru dapat mempertimbangkan untuk diterapkannya model pembelajaran TGT di kelas pada materi tertentu. Harapannya, siswa dapat memperoleh hasil yang baik dalam hal akademik maupun aplikatif.

\section{KESIMPULAN DAN SARAN}

Berdasarkan hasil penelitian mengenai analisis kemampuan pemecahan masalah matematis siswa kelas X IPA 1 di SMA Muhammadiyah 1 Purwokerto pada pokok bahasan fungsi komposisi, dapat diambil beberapa kesimpulan bahwa siswa dengan prestasi yang rendah akan memiliki kemampuan pemecahan masalah matematis yang kurang baik artinya siswa hanya dapat memahami masalah. Siswa dengan prestasi yang sedang, memiliki kemampuan pemecahan masalah matematis yang cukup baik artinya siswa dapat memahami masalah, merencanakan masalah, dan melaksanakan rencana untuk mengerjakan soal tetapi dalam melaksanakan rencana masalah masih terdapat beberapa kekeliruan. Sedangkan siswa dengan prestasi belajar yang tinggi, memiliki kemampuan pemecahan masalah matematis yang baik artinya siswa memahami masalah dengan baik, merencanakan masalah, dan melaksanakan rencana masalah untuk mengerjakan soal.

\section{DAFTAR PUSTAKA}

Armita, U.Y. \& Marsigit, M. (2016). Keefektifan PBL Setting STAD dan TGT ditinjau dari Prestasi, Berpikir Kritis, dan Self-Efficacy. Jurnal Pendidikan Matematika dan Sains 4(1), 1-11.

Bakoban, F. I., \& Amry, Z. (2017). Perbandingan Kemampuan Pemecahan Masalah Matematika Siswa Menggunakan Model Pembelajaran Kooperatif Tipe Student Teams Achievement Division Dengan Teams Games Tournaments Di SMP Negeri 35 Medan. Inspiratif, 3(2), 68-79.

Isjoni. (2009). Cooperative Learning Efektivitas Pembelajaran Kelompok. Bandung: Alfabeta.

Ismawati, D. Y. (2014). Perbedaan Kemampuan Pemecahan Masalah Matematis Siswa Menggunakan Pendekatan Diskursif Metode Two Stay Two Stray Dengan Pembelajaran Konvensional (Skripsi). Universitas Pendidikan Indonesia, Bandung. 
Kim, D. H. (2012). Improvement in problem solving and critical thinking among Korean nursing students over an academic year. Educational Research Journal, 2(8), 257-265.

Polya, G. (1973). How to Solve it. A new aspect of mathematical method (second). New Jersey: Prence University Press.

Rahmawati, N.K. (2017). Implementasi Teams Games Tournaments dan Number Head Together ditinjau dari Kemampuan Penalaran Matematis. Al-Jabar: Jurnal Pendidikan Matematika, 8(2), 121134.

Rustinah. (2016). Meningkatkan Hasil Belajar Matematika Melalui Penerapan Metode Team Game Turnament Pada Siswa Kelas VII.1 SMP Negeri 3 Batanghari Tahun Pelajaran 2012/2013. AKSIOMA: Jurnal Program Studi Pendidikan Matematika 5(1), 40-51.

Slavin, E. R. (2008). Cooperative Learning Teori Riset dan Praktik. Bandung: Nusa Media.

Slavin, R. E. (2008). Cooperative Learning (Terjemahan). Bandung: Penerbit Nusa Media.

Sugiyono. (2012). Metode Penelitian Kuantitatif Kualitatif dan $R \& D$. Bandung: Alfabeta.
Suji, Nirawati, R., \& Mariyam. (2017). Penerapan Model Pembelajaran Kooperatif Tipe Teams Games Tournament Untuk Meningkatkan Kemampuan Pemecahan Masalah Matematis Siswa Pada Materi Segitiga. Jurnal Pendiidikan Matematika Indonesia, 2(September), 63-71.

Tampubolon, P. (2013). Upaya Meningkatkan Kemampuan Pemecahan Strategi Kooperatif Tipe TGT (Team Games Tournament). In Seminar Nasional Sains dan Pendidikan Sains VIII (Vol. 4, pp. 139-148). Salatiga: Fakultas Sains dan Matematika, UKSW.

Trisnawati \& Wutsqa, D.W. (2015). Perbandingan Keefektifan Quantum Teaching dan TGT Pada Pembelajaran Matematika Ditinjau dari Prestasi dan Motivasi. Jurnal Riset Pendidikan Matematika 2(2), 297-307.

Warli. (2013). Kreativitas Siswa SMP yang Bergaya Kognitif Reflektif atau Impulsif dalam Memecahkan Masalah Geometri. Jurnal Pendidikan dan Pembelajaran, 20(2), 190-201. 